\title{
Multi-model evaluation of longitudinal temperature fluctuations and the dominant influencing factors among Michigan streams
}

\author{
Ryan Andrews ${ }^{1}$, Daniel Hayes ${ }^{2}$, and Troy Zorn ${ }^{3}$ \\ ${ }^{1}$ Oregon Water Resources Department \\ ${ }^{2}$ Michigan State University \\ ${ }^{3}$ Michigan Department of Natural Resources
}

October 27, 2021

\begin{abstract}
Stream temperature is an important determinant of fish growth, migration, and survival, and can thus impact the structure and function of stream ecosystems. Fluctuations in water temperature can occur spatially and temporally, occurring naturally or because of anthropogenic pressures. Many streams in Michigan and elsewhere in North America receive groundwater inputs that help regulate instream conditions by stabilizing discharge as well as stream temperature. However, groundwater withdrawal through high-capacity wells is important to the agricultural industry and water users for irrigation or municipal water supplies. Withdrawal can cause reductions in streamflow which typically results in increased stream temperature. Other atmospheric and hydrologic variables (i.e. overland discharge) also impact the rate at which stream temperature changes as it flows downstream. In this study we deployed paired up- and downstream water pressure and temperature loggers within 21 stream reaches throughout the state of Michigan to quantify and model relationships between stream discharge, air temperature, and longitudinal change in stream temperature (i.e., temperature flux). Using multi-model selection criteria, we evaluated the performance of a hierarchical suite of models that predict temperature flux rates as a function of potential driving variables. The multi-model selection criteria identified a best-fitting model that was able to model the diurnal, seasonal, and annual variations in rates of longitudinal temperature fluctuations across a majority of sample streams. Partial regression analysis indicated that proxy variables representing solar radiation at the stream surface were generally the most influential predictors of longitudinal changes in stream temperature, but air temperature and components of streamflow including groundwater input were significant predictors and important in many streams.
\end{abstract}

\section{Introduction}

Water temperature is a critical determinant of the structure and function of stream ecosystems. Water temperature has an influence across all trophic levels in streams, from bacteria to fishes, with particularly important implications for stenothermic organisms such as salmonids that have a relatively narrow range of optimal temperature. Although stream temperature varies naturally in response to numerous hydrological and meteorological factors, humans are having an increasing impact through anthropogenic drivers such as surface and groundwater removal, climate change, changes in land cover and impoundments. Changes in stream thermal regimes due to anthropogenic influences can impact biological, physical and chemical processes, as well as overall health of aquatic ecosystems (e.g., Beaupré, St.-Hilaire, Daigle, \& Bergeron, 2020; Caissie, 2006; Naiman, Magnuson, McKnight, \& Stanford, 1995) As such, it is important to understand the impact human activities have on stream temperatures relative to natural variation within and across streams.

In order to successfully protect against negative impacts to a stream's natural thermal regime and associated biota, resource managers and policy makers must better understand the ways natural and anthropogenic 
factors influence stream temperature. The initial impetus for our research was on the effects of groundwater withdrawal and potential reductions to baseflow on stream temperature as this is an increasing area of concern in Michigan and elsewhere in the nation. As demands for groundwater increase due to effects of land and water use and climate change, there is a need to understand the impacts of water withdrawal on stream thermal dynamics. Although a number of stream temperature models are available (e.g., Beaufort, Curie, Moatar, Ducharne, Melin, \& Thiery, 2016; Beaupré et al., 2020; Herb \& Stefan, 2011; Marcé \& Armengol, 2008) relatively few explicitly incorporate the effects of the volume of groundwater input on stream temperature. Further, results from these studies highlight the varying impact of different components of stream heat budget across different hydrologic and geomorphic settings, emphasizing that models of different complexity may perform better in different streams.

Previous research has generally approached the problem of modeling stream temperature by identifying physical processes thought to be important and developing a single model based on these forcing functions. For example, the Stream Network Temperature (SNTEMP) model (Theurer, Voos, Kenneth, \& Miller, 1984) is a deterministic model that incorporates key meteorological variables as processes that contribute to a stream's thermal budget. Similarly, an equilibrium temperature approach (e.g., Edinger, Duttweiler, \& Geyer, 1968; Herb \& Stefan 2011) has been adopted to provide model solutions to the complex problem of thermal budgeting. While following a reductionist approach that has proven successful in many fields such as experimental physics is intellectually appealing, there are practical limitations to implementing this in a natural setting. One impediment is the level of detail needed in the data to drive such models (Beaupré et al., 2020). In theory, factors such as wind velocity or relative humidity need to be measured at the water-air interface, and at multiple points along a given stream reach. Similarly, stream shading and cloud cover affect stream heating by solar input and nighttime cooling by longwave radiation, but these factors vary over both short time scales (e.g., cloud cover can vary rapidly within a day) and longer time scales (e.g., seasonal changes in foliage) and longitudinally along a stream reach.

Because of these limitations, recent research has explored incorporating a statistical component into stream temperature models. Two examples include Beaupré et al. (2020) and Marcé and Armengol (2008), both of which compared the performance of deterministic models to statistical or hybrid stream temperature models. Both found that models that included a statistical component performed better than deterministic models. As such, one of our major goals was to develop an approach that used elements of a process-based model to incorporate the effects of groundwater inputs, and to implement this model within a statistically based framework. As highlighted above, data are often limited in availability or expensive to acquire, and as such, there is value in understanding how simpler models requiring fewer inputs perform in comparison to more parameter-rich models. Such an evaluation is useful by offering insight into the benefit gained by collecting data to increase parameterization, which can oftentimes become expensive in terms of time and resources. However, as more data becomes readily available through technological improvements in remote sensing and geographic information systems, it may become more feasible to develop increasingly complex predictive models. As such, we also sought to evaluate the impact of model complexity on performance metrics, a situation that a statistical multi-model inferential framework is well suited to address (Burnham \& Anderson, 2002). One strength of this approach is that the model selection procedure simultaneously considers goodness of fit and parsimony of the model (e.g., Thayer, Taylor, Hayes, \& Haas, 2007).

Our interest in understanding stream temperature dynamics led us to model the flux rate (i.e., change in temperature between upstream and downstream) as a function of hydrologic and atmospheric variables. Further, we applied this modeling approach to several rivers in Michigan that were thought a priori to encompass a range of groundwater input based upon the wide range of physiographic characteristics and estimations of well yields throughout the state (see Section 2.1). The objectives of this study were to 1) collect streamflow and temperature data to develop statistical models of longitudinal stream temperature change; 2) evaluate the performance of a suite of models representing flux rate as a function of potential driving variables; and 3) identify dominant processes influencing rates of longitudinal stream temperature change. 


\section{Methods}

2. 1 Study region and data collection

Michigan is located in the Upper Midwest region of the United States. Hydrologic features throughout Michigan are variable, with groundwater inputs to streams being dependent upon permeability of geologic deposits and local topography (Seelbach, Wiley, Kotanchik, \& Baker, 1997) and surface water availability being driven by precipitation and climate. Many streams located within the northern Lower and Upper Peninsulas have groundwater-driven flow regimes due to coarse-textured glacial deposits dominating the local geology. Yields from groundwater wells in these regions can reach nearly 500 gallons per minute compared to 10 gallons per minute in Southeastern Michigan where confining material dominates (Michigan Department of Environmental Quality, 2005).

Although Michigan's landscape has a diverse mosaic of surficial deposits which can explain baseflow contributions to nearby streams, climatic variability is relatively low. Average air temperatures in the Lower Peninsula range from $15.9{ }^{\circ} \mathrm{C}$ to $19.3^{\circ} \mathrm{C}$, while temperatures in the Upper Peninsula are consistently cooler. Annual groundwater temperatures range from $11.1{ }^{\circ} \mathrm{C}$ in the southern Lower Peninsula to $5.6{ }^{\circ} \mathrm{C}$ in the Upper Peninsula (Collins, 1925).

In total, data were obtained for 21 streams spanning a broad geographical range throughout Michigan (Figure 1). Site information for each stream reach is displayed in Table 1, including latitude, longitude, reach length, and annual groundwater temperature based on Collins (1925). Data were collected using a network of paired streamgages installed at upstream and downstream locations within each stream over the summer and fall of 2015 and 2016. Visual inspection of topographic maps ensured that upstream and downstream locations were situated absent of tributaries entering the reach. In 2015, data were collected from 13 streams beginning in late July and extending into early November. In 2016, data were collected from 19 streams beginning in May and extending through October. Water temperature and pressure data were collected using $\mathrm{HOBO}^{\circledR}$ U20 Water Level Loggers at 15-minute intervals but were averaged to hourly intervals. Data loggers were calibrated against each other using an ice bath that slowly warmed to room temperature. All loggers agreed within $\pm 0.18{ }^{\circ} \mathrm{C}$ and were corrected for observed constant offsets. The loggers were housed in streamgages designed using PVC piping attached to a fence post driven into the stream bed. Holes were drilled into the bottom of the streamgages with mesh lining wrapped around to prevent sediment build up while allowing water to flow through. Staff rulers were attached to the exterior of the streamgages for reference when developing stage-discharge curves. Air temperature and barometric pressure data were collected at one of the paired locations for each stream reach using Monarch ${ }^{\circledR}$ Track-It data loggers. Temperature and pressure data were collected at 15-minute intervals, but values were averaged to hourly intervals.

In this analysis, longitudinal stream temperature change was calculated as the difference between the downstream and upstream gage within each stream for each hourly interval. Flux rate $\left(\Delta T={ }^{\circ} \mathrm{C} / \mathrm{km}\right)$ was calculated as the change in temperature per stream kilometer, such that positive numbers represent an increase in temperature (i.e., warming) in the downstream direction, and negative numbers represent a decrease (i.e., cooling). As the U20 loggers measure total pressure, water depth was estimated by subtracting barometric pressure from total pressure and converting to meters of water (i.e., river stage). Barometric pressure readings were subtracted from total pressure (water and air) readings collected from submerged data loggers to calculate true water pressure. The true water pressure was converted to meters of water which was then adjusted to reflect staff gage readings collected during site visits for discharge measurements. Discharge measurements were taken 3 to 5 times each year to capture various river stages at each of the upstream and downstream locations of each stream reach to develop stage-discharge relationships (Rantz, 1982). Stream velocity was measured using a SonTek ${ }^{\circledR}$ Flowtracker at $20-30$ points across the stream channel, and discharge was calculated. The stage-discharge relationships were estimated using a power function (equation (1)):

$Q=a G^{b}$ (eq. 1)

where $Q=$ discharge $\left(\mathrm{m}^{3} / \mathrm{s}\right)$ and $G=$ gage reading $(\mathrm{m})$, while $a$ and $b$ are parameters estimated by a power function relating discharge to stream stage. Power functions were also developed to estimate width and depth 
as a function of discharge (equations 2-3):

$w=c Q^{e}($ eq. 2$)$

$d=f Q^{h}$ (eq. 3)

where $w$ is width $(\mathrm{m}), d$ is depth $(\mathrm{m})$, and $c, e, f$, and $h$ are parameters estimated using a power function.

\subsection{Model variables}

Broadly speaking, thermal dynamics are affected by heat exchange processes that occur at the air-water and streambed-water interface and are dependent upon stream discharge. Stream temperature is influenced by any process that influences heat load of the stream or discharge in the stream channel (Poole \& Berman, 2001). Consequently, the change in stream temperature between two points is impacted by numerous hydrological and meteorological factors including stream and groundwater discharge, solar radiation, channel slope and riparian vegetation, among others (Caissie, 2006).

All stream discharge is derived by precipitation; however, the pathways by which precipitation enters the stream channel can vary among local catchments. As such, longitudinal changes in stream temperature are influenced by the mixing of water with different temperature signatures resulting from the path of entry into the stream. The temperature of groundwater inputs from the phreatic aquifer of a stream catchment is typically the baseline from which stream temperature deviates (Poole \& Berman, 2001). Other sources of discharge (i.e., overland flow) enter the stream channel longitudinally and carry with them different heat energies causing thermal fluctuations of the discharge in the stream channel. Additionally, as discharge flows downstream, heat exchange between the air-water and streambed-water interface generally increases stream temperature during summer months.

\subsubsection{Atmospheric variables}

\section{Air temperature}

The rate at which stream temperature change occurs is directly proportional to the difference between air and water temperature. A single variable $\left(T_{a}-T_{w}\right)$ was incorporated to capture the effect of the air-water temperature differential. Throughout this paper, $\left(T_{a}-T_{w}\right)$ is computed with $T_{w}=T_{u p}$. The coefficient determining this rate was estimated via regression.

\section{Shortwave radiation}

Shortwave radiation, usually in the form of direct solar radiation, typically dominates the heat budget of streams during summer, and can be the largest determinant of stream temperature (Johnson, 2004; Wondzell, Diabat, \& Haggerty, 2019). We accounted for the effects of solar radiation without having direct measurements of solar heat flux by calculating sun altitude angle and day length for each site. Altitude angle $(a)$ and day length $(S)$ were computed for each hour of day and each day of year, respectively, from Meeus (1999). Given that the amount of solar radiation reaching the stream channel also depends on several unmeasured variables, particularly degree of stream shading, we estimated the coefficient representing the proportion of solar radiation reaching the stream via regression.

\subsubsection{Hydrologic variables}

\section{Upstream discharge}

We derived several variables related to reach scale hydrology using discharge data collected from the paired streamgages. The ratio of upstream to downstream discharge $\left(Q_{u p} / Q_{\text {down }}\right)$ and the difference between downstream and upstream discharge $\left(Q_{\text {down }}-Q_{u p}\right)$ were both used as indicators of gain or loss in discharge, since inputs to the stream may alter the thermal dynamics of the stream. An additional parameter was incorporated to reflect only the upstream discharge as the volume of water in the stream would be expected to influence the relative thermal inertia of the stream (e.g., Stefan \& Preud'homme, 1993).

\subsubsection{Effects of discharge sources}


Since thermal patterns from various sources of discharge can affect stream temperature differently, we created parameters for heat energy contributions of baseflow, overland flow, and discharge originating from upstream. To account for stream temperature change induced by energy input of different sources of discharge, we weighted the heat energy contributions based on water temperature and overall discharge at the downstream location. Since heat load is a measure of heat energy added to a stream, we then subtracted the upstream temperature to estimate the relative change in temperature theoretically induced by heat energy inputs of each source of discharge. For example, the heat energy of discharge originating from upstream was calculated as follows (equation (4)):

$\Delta_{v \pi}=\left[\left(Q_{u p} T_{u p}\right) / Q_{\text {down }}\right]-T_{u p}$ (eq. 4$)$

where $\Delta_{v \pi}$ is the temperature change induced by the heat energy of upstream discharge, $T_{u p}$ is the water temperature $\left({ }^{\circ} \mathrm{C}\right)$ measured at the upstream gaging station, and $Q_{u p}$ and $Q_{\text {down }}$ are the discharges $\left(\mathrm{m}^{3} / \mathrm{s}\right)$ measured at the respective gaging stations. Similar metrics were computed for baseflow $\left(\Delta_{\beta a \sigma \epsilon}\right)$ and overland flow $\left(\Delta_{o \in \rho}\right)$.

Baseflow

Baseflow discharge $\left(Q_{b a s e}\right)$ was estimated within each stream reach by determining the gain in discharge between gaging stations for the lowest 7-day flow period for each year when downstream discharge was greater than upstream discharge. We chose this method to represent baseflow gain in each stream reach because this is typically the period during which streamflow is primarily sustained by groundwater discharge to the stream. Without direct measurements of baseflow within relatively short stream reaches, and because baseflow can vary over a range of time scales and due to human activities like diversion and withdrawal and natural processes such as evapotranspiration, we did not account for seasonal fluctuations in baseflow. Thus, 7-day moving averages of $Q_{\text {down }}$ and $Q_{u p}$ were calculated by year for each day and the minimum difference was determined to be representative of baseflow gain for the year. The temperature of baseflow, $T_{\text {base }}$, was set as a constant related to the regions where each stream is located throughout Michigan based off of previous research $\left(\mathrm{UP}=5.6{ }^{\circ} \mathrm{C} ; \mathrm{NLP}=8.3{ }^{\circ} \mathrm{C} ; \mathrm{SLP}=11.1{ }^{\circ} \mathrm{C}\right.$ [Collins, 1925]).

\section{Overland flow}

The residual flow remaining after subtracting $Q_{u p}$ and $Q_{b a s e}$ from $Q_{\text {down }}$ was considered as overland flow, $Q_{\text {over }}$ . This represents the surface water runoff gained between the up and downstream gages. The temperature of the overland flow, $T_{\text {over }}$, is unknown, but we assumed that a 12-hour moving average of air temperature would represent the temperature of this component. The lag time associated with the 12-hour moving average was assumed to account for the heat gained by overland surface runoff over the time it would take to reach the stream channel. Occasionally, we observed periods during which upstream discharge was greater than downstream discharge, in which case the heat energy was calculated as zero for both of these parameters.

\subsection{Regression models}

A series of statistical models was developed to represent longitudinal stream temperature flux rates $(\Delta T$ ) based on hypothesized mechanisms that affect stream temperature dynamics. We used multiple linear regression analysis to construct models to predict flux rates $\left({ }^{\circ} \mathrm{C} / \mathrm{km}\right)$. Models were built in a hierarchical fashion sequentially incorporating parameters for processes judged to be important in influencing flux rates such as air temperature, a range of flow components contributing to overall discharge in the stream channel, and atmospheric conditions. Models were parameterized for each process contributing to temperature change and were individually fit to each stream. All parameters of the models were considered unknowns, including an intercept and the coefficients corresponding to the components contributing to temperature change. Nonlinear optimization (statspackage; R Core Team, 2013) was used to estimate values for each parameter to minimize the sums of squares between observed and predicted flux rates.

\subsubsection{Base model (model 1)}

As a base model, the air-water temperature differential, $\left(T_{a}-T_{w}\right)$, was related to downstream temperature 
change using linear regression, as in the following equation (equation (5)):

$\Delta T=\beta_{0}+\beta_{1}\left(T_{a}-T_{w}\right)($ eq. 5$)$

The base model was the simplest model, and subsequent models became progressively complex by incorporating additional variables (Table 2 ).

\subsubsection{Discharge ratio (model 2)}

In this model, the ratio of downstream to upstream discharge was included as a variable to represent the potential influence of differences in discharge between sample sites as a moderator to temperature flux. By taking a ratio of discharges, this variable was represented as a dimensionless factor in the model. Increases in discharge may increase the thermal inertia of the stream, while losses in discharge can increase the residence time of discharge in the stream reach and exposure to heating sources.

\subsubsection{Upstream discharge (model 3)}

A variable representing upstream discharge was included since variations in stream temperature have been shown to be inversely proportional to stream discharge (Poole \& Berman, 2001). Another variable, $\Delta_{\varphi \lambda \text { дo }}$, was added to account for the cumulative heat energy of the stream (equation (6)) based on the source of discharge gain. Thermal contributions of various sources of discharge were weighted depending upon their proportional contribution to overall discharge.

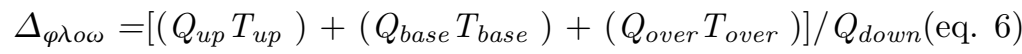

\subsubsection{Discharge differential (model 4)}

In this model, the gain or loss in discharge between upstream and downstream locations was incorporated to account for thermal flux when discharge is lost or gained throughout the reach. This parameter is similar in intent to the discharge ratio included in model 2 (Table 2), but retains the dimension of discharge, and as such, would vary across streams of different size.

\subsubsection{Day length and altitude angle (models 5, 6, and 7)}

Day length $(S)$ was included in model 5 as a proxy to account for the effects of solar radiation, without having direct measurements of solar heat flux. A separate parameter representing the sun's altitude angle $(a$

) was implemented as a measure of solar radiation for each hour of each day of year in model 6 , and model 7 incorporated both parameters.

\subsubsection{Differential thermal effects of sources of discharge (models 8, 9, and 10)}

Models 8, 9, and 10 included separate parameters for the thermal effects of each of the three components of overall stream discharge (i.e., temperature contributions of upland discharge, base flow, and overland flow). These models then included either one or both of the day length and altitude angle parameters.

\subsubsection{Incorporating components of heat flux (model 11)}

In model 11, we attempted to represent longitudinal temperature change using principles of an energy balance equation adapted from the methods of Magnusson, Jonas, \& Kirchner (2012), which was developed to estimate downstream temperature change as a function of surface heat transfer and frictional heating. The downstream temperature change over a stream reach of length $L(\mathrm{~m})$ and average width $w(\mathrm{~m})$ can be estimated using equation (7):

$\Delta T(t)=(q(t) w(t) L) /(Q(t) \varsigma \rho)+(\gamma \Delta \zeta) / c+\Delta T_{\rho}(t)($ eq. 7$)$

where $q\left(\mathrm{~W} / \mathrm{m}^{2}\right)$ represents the total heat flux across the stream surface, $c(\mathrm{~J} / \mathrm{kg} \cdot \mathrm{K})$ is the specific heat capacity of water, $\rho\left(\mathrm{kg} / \mathrm{m}^{3}\right)$ is the density of water, $\Delta \zeta(\mathrm{m})$ is the difference in altitude between the upstream and downstream ends of the stream reach, $g\left(\mathrm{~m} / \mathrm{s}^{2}\right)$ is the gravitational acceleration, and $\Delta T_{\rho}\left({ }^{\circ} \mathrm{C}\right)$ is the residual temperature change. 
In this study, we considered the following four components of surface heat exchange:

$q=L E+H+S W_{\text {net }}+L W_{\text {net }}$ (eq. 8)

where $L E$ is latent heat flux $\left(\mathrm{W} / \mathrm{m}^{2}\right), H$ is sensible heat flux $\left(\mathrm{W} / \mathrm{m}^{2}\right), S W_{\text {net }}$ is net shortwave radiation $\left(\mathrm{W} / \mathrm{m}^{2}\right)$, and $L W_{\text {net }}$ is net longwave radiation $\left(\mathrm{W} / \mathrm{m}^{2}\right)$. Although equation (8) explicitly predicts how temperature will change along a stream reach, we attempted to estimate longitudinal temperature flux by incorporating these principles into a statistical regression model. The regression model was developed based on the principle that surface heat exchange warms or cools the stream at a rate that is proportional to the heat flux and inversely proportional to discharge. It is important to note that the stream energy balance equation assumes constant discharge and steady state conditions. Thus, we included additional drivers of heat exchange, including the air-water temperature differential, baseflow heat energy, and overland flow heat energy to account for any residual temperature change which cannot be explained by surface heat exchange (equation (9)). Given that longitudinal temperature flux was approximated using regression equations, and sensible heat flux is dependent upon latent heat flux, $H$ was not included in model 11. Additionally, the other components of the stream energy balance equations which remained constant, including the specific heat capacity of water, the density of water, altitude difference, and gravitational acceleration, were excluded from the model. Altitude angle was used as a proxy for net shortwave radiation.

$\Delta T=\beta_{0}+\beta_{1}\left(T_{a}-T_{w}\right)+\beta_{7}\left(\Delta_{\beta a \sigma \epsilon}\right)+\beta_{8}\left(\Delta_{o \epsilon \rho}\right)+\beta_{10}\left[\left(T_{w}+273.16\right)^{4} / Q_{u p}\right]+\beta_{11}\left[\left(\exp \left(T_{w}\right)-\exp \left(T_{a}\right.\right.\right.$ )$\left.) / Q_{u p}\right]+\beta_{12}\left(\alpha / Q_{u p}\right)$ (eq. 9$)$

\subsection{Model fitting and selection}

We evaluated the performance of the aforementioned models representing flux rate as a function of potential driving variables. The first step in model fitting was to estimate model parameters by minimizing the residual sums of squares between modeled and observed $\Delta T$ at the hourly time step. All parameters were considered free fitting coefficients, so no constraints were placed on possible values. Next, we applied a model selection procedure using Akaike's Information Criterion (AIC) (Akaike, 1998). AIC was used because it prioritizes models based on fitting ability and level of parsimony (see Burnham \& Anderson, 2002; Thayer et al., 2007). AIC was calculated using equation (10), which incorporates the likelihood $(L)$ (equation (10)), omitting fixed constants.

$A I C=2 k-2 \ln (L$ (parameters $\mid$ data $))($ eq.10)

$L($ parameters $\mid$ data $)=-(n / 2) \log _{\mathrm{e}}(R S S)($ eq. 11$)$

where $k$ is the number of unknown parameters, $n$ is the sample size (number of hourly observations), and $R S S$ is the residual sums of squares between modeled and observed $\Delta T$. Using the above criteria, the model with the lowest AIC score was judged to fit the observed data best. Further, the weight of evidence of any given model, $\omega_{l}$, (equation (12)) was used to compare each model's fitting ability relative to the suite of models considered:

$\omega_{i}=\frac{\exp \left(-\frac{i}{2}\right)}{\sum_{m}^{M} \exp \left(-\frac{i}{2}\right)}($ eq. 12$)$

where $M$ is the total number of models and $\Delta \imath$ is the difference in AIC of any given individual model compared with that of the best model.

2.5 Identifying dominant factors

Partial $R^{2}$

Partial regression analysis (QuantPsyc package; Fletcher, 2012) was used to assess the influence of each of the variables included in the best model identified as best fitting observed longitudinal thermal flux rates. Partial $\mathrm{R}^{2}$ values are useful for understanding the residual variation accounted for by a predictor variable that cannot be explained by a constrained model. In other words, the partial correlation coefficient is useful because it allows for directly estimating the proportion of unexplained variation of the dependent variable that becomes explained by the addition of an independent variable to the model. In order to determine the 
partial $\mathrm{R}^{2}$ of a particular predictor variable, the proportion of residual variance can be accounted for by $(S S R-S S E) / S S R$, where $S S R$ is the sums of squared errors of the reduced model, and $S S E$ is the sums of squared errors of the fully parameterized model. Values represent the proportion of variation which cannot be explained by the predictors in the reduced model when compared to the full model.

\section{Results}

\subsection{Observations of thermal and hydrological data}

Individual stream reaches used in this study displayed a wide range of discharges, from $0.01-1.79 \mathrm{~m}^{3} / \mathrm{s}$ (Table 3). Interestingly, the Carp River, East Branch Black River, Pokagon Creek, and North Branch Thunder Bay River experienced on average a loss in discharge in the downstream direction (Table 3). While the volumes of water lost in losing reaches were relatively small, Carp River experienced a $25 \%$ loss in discharge, on average. In contrast, five stream reaches experienced gains in discharge of more than double the measured upstream discharge. Of these, Cedar Creek experienced the greatest proportional gain in discharge, followed by Slapneck Creek, Squaw Creek, Hasler Creek, and Butterfield Creek.

Streams displayed a wide range of channel characteristics as exhibited by measurements of width and depth. Stream width ranged from a minimum of $3.25 \mathrm{~m}$ (Honeyoey Creek) to a maximum of $12.00 \mathrm{~m}$ (Fish Creek), while depths ranged from $0.20 \mathrm{~m}$ (King Creek) to $0.60 \mathrm{~m}$ (East Branch Black River). Likewise, widthto-depth ratios varied from streams that were relatively narrow and deep to wide and shallow. Honeyoey Creek had the minimum width-to-depth ratio at 10.16, exhibiting characteristics of relatively narrow and deep channelization, while Nottawa Creek displayed the greatest width-to-depth ratio at 31.60 (Table 3) indicative of a relatively wide and shallow stream channel.

Observations of flux rates varied temporally by month and spatially by individual stream reach (Table 4). A majority of streams (14 of 21) displayed longitudinal stream warming, while the remaining seven showed a pattern of downstream cooling over the entire study period. Although the seasonal flux rates varied among streams, the mean flux rate across all streams showed the highest degree of warming in July and August, with other months showing a mean flux rate of nearly zero (Table 4).

Observations of longitudinal flux rates and average trends were variable by individual streams, as illustrated for representative streams (Figure 2). Diurnal variations in flux rate showed an alternation between daytime warming and nighttime cooling in most of the streams (Figure 2), except for Nottawa Creek which consistently showed a downstream cooling trend. LOESS regressions provided a smoothed representation of the hourly data highlighting general seasonal patterns. Some streams, such as the Cedar and Prairie Rivers displayed a pattern of peak rates of warming in the summer and trended towards little or no fluctuation in the spring and fall. In contrast, Nottawa Creek displayed peak cooling tendencies across both years during the summer, and the Carp River showed no clear seasonal pattern (Figure 2). Observations also indicate interannual variability in patterns of flux rates, as evidenced by the Prairie River, which experienced a higher peak rate of warming in the summer of 2016 compared to 2015 (Figure 2).

Univariate plots of longitudinal stream temperature flux rates in relation to atmospheric and hydrologic variables showed considerable variation, and as the example in Figure 3 illustrates for the Cedar River, there was not a clear influence of any single variable on flux rate. These plots did not show any clear signs of non-linearity in the relations among the driving variable and flux rate.

\subsection{Model fit and selection}

The fit varied widely between models (Table 5); averaged across all streams, $\mathrm{R}^{2}$ ranged from a minimum of 0.07 (Model 1) to a maximum of 0.41 (Model 10). As expected, model fit and ability to track trends improved as parameterization increased, as shown for the Cedar River (Figure 4). Models that ranked highly contained separate parameters representing each of the individual components of stream heat load (upstream flow, baseflow, and overland flow) as well as at least one parameter to represent heat exchange at the stream surface (e.g., day length and/or sun altitude angle). The weight of evidence heavily favored Models 10 and 11, which contained the most parameters and received the greatest weights in 15 (71\%) 
and 5 (24\%) streams (Table 5), respectively, while Model 9 received the greatest weight in a single stream. The best model (Model 10) was the most complex in terms of model parameters, however improved model performance offset his additional complexity as indicated by AIC values. The second-best model (Model 11) was based upon variables derived to represent the principles of surface heat exchange and an energy balance equation.

Model 10 generally tracked trends well for streams with multiple years of data (Figures 4, 5) but would occasionally underestimate peak rates of both warming and cooling. The model produced a maximum $\mathrm{r}-$ squared of 0.77 and a minimum of 0.13 , while averaging an r-squared of 0.41 across all streams. The inclusion of individual components of stream heat load (as opposed to a single lumped variable) as well as components accounting for solar heating appeared to improve model ranking and fit (Table 5; Figure 4). Among many streams, the model tended to track trends and capture seasonal and interannual variability better than other models. The model captured a wider range of variability which allowed for more improved fit to seasonal peaks, although the timing was occasionally earlier or later than observed.

The second-best model (Model 11) was based on prior physical models and included parameters to emulate solar, longwave, and evaporative heat flux along the longitudinal stream gradient. Additionally, this model included parameters for the base flow and overland flow components of stream heat load. Model 11 did not track trends quite as well as the best model, particularly late in the season (Figure 4). The third-best model (Model 9) contained only one parameter to account for solar heat flux (sun altitude angle) and was the only other model to account for the greatest weight for any study stream (Squaw Creek). Overall, this model captured trends nearly as well as the best model, but more often failed to capture peaks in flux rates and failed to capture the full range of flux rates in many streams.

\subsection{Dominant influencing factors}

The influence of each variable included in Model 10 on the rate of longitudinal temperature flux was examined through partial regression analysis. On average, variables incorporating aspects of shortwave radiation (i.e., day length and sun altitude angles) captured the greatest proportion of variation in flux rates across all streams (Table 6). Day length was identified as the factor explaining the greatest proportion of variance in six streams, while altitude angle was the second leading influencing factor in four streams. The variables accounting for baseflow and overland flow heat contributions each explained the greatest proportion of variation in three streams and explained a moderate amount of variation on average across all streams. Although upstream discharge $\left(Q_{u p}\right)$ explained the greatest variation in two streams, it explained relatively

little variation in others. Finally, the discharge differential $\left(Q_{\text {down }}-Q_{u p}\right)$ and the thermal effects of upstream discharge $\left(\Delta_{v \pi}\right)$ explained little variation in flux rates relative to the other variables in the fully parameterized model.

\section{Discussion}

4.1 Influence of thermal, hydrological, and meteorological conditions

Our data encompassing a relatively large number of streams with observations across years and seasons provided a robust data set for calibrating the suite of statistical models we evaluated using parameters meant to reflect processes thought to influence stream temperature along a longitudinal gradient. We developed a suite of successively complex models representing internal and external drivers of heat exchange (Poole \& Berman, 2001). In doing so, we were able to determine the relative importance of these factors in influencing rates of thermal flux. Identifying major factors contributing to potential stream warming is critical in developing environmental policies for protection against adverse impacts to water resources.

Although there was no single best predictor for all streams, sun altitude angle or day length were the best predictors of flux rates for most streams. Each of these variables represents aspects of solar heat flux reaching the stream surface. Day length was identified as a strong predictor of hourly stream temperatures in a previous study by Risley, Constantz, Essaid, \& Rounds (2010) to assess the impacts of groundwater pumping on stream temperatures. Similarly, Bustillo, Moatar, Ducharne, Thiéry, \& Poirel (2014) found that 
the inclusion of day length improved the precision and accuracy of a statistical model of stream temperature. Day length and sun angle are completely dependent on latitude, day of year and the time of day. As such, they are outside of human control, but it is important to note that modifying factors such as riparian shading, which can be influenced by humans, can reduce the warming effects of solar radiation.

The relative influence of other potential drivers varied widely among streams, with no single variable or set of variables emerging as next in importance. The lack of a single best predictor suggests that the processes that dominate the dynamics of stream temperature vary across streams. We have shown that variations in hydrological conditions, such as discharge, play an important role in stream temperature dynamics. Although heat energy from overland flow and baseflow ranked as moderately influential factors overall, they were the most influential variables in several streams. The diverse geographic coverage of the stream reaches in this study likely contributed to the fact that there was no single best predictor, since streams were located among a variety of geologic landscapes and land uses that impact local hydrology.

We observed variability in longitudinal flux rates indicative of diurnal, seasonal, and annual variations, as well as spatial variability among individual streams. Overall, flux rates showed an inverse relationship with discharge, such that rates of heating and cooling showed less variability as discharge increased; however, relationships between flux rates and other variables were less obvious. Flux rates generally peaked in late summer, while trending towards zero fluctuation on average in spring and late fall. Although many streams showed peak rates of warming during summer months, several streams experienced downstream cooling. For example, while Nottawa Creek consistently experienced rates of cooling, the effect was greatest during the summer across both years (Figure 2). Interestingly, it also had the greatest width-depth ratio (Table 3) which would, in theory, expose the stream surface to a greater amount of solar radiation causing a greater degree of warming. Further investigation of the causes of cooling (e.g., shading, baseflow input) may offer insight into options for minimizing impact of human activities on stream temperature.

Of all the processes of heat exchange, input of cold groundwater is the primary mechanism that can consistently cool a stream in a downstream direction. As such, maximizing groundwater input to streams provides the greatest degree of cooling potential in streams. Evaporative cooling provides an additional mechanism but does not generally result in cooling consistently enough to result in seasonal averages being decreased. Similarly, exposure to the night sky leads to black body cooling, which was evident at night across short periods in some streams but does not lead to consistent cooling. Among other potential drivers under human control, stream shading likely provides the best buffer for reducing the magnitude of thermal fluctuation. Although stream shading does not produce a cooling effect, and thus cannot explain reduced downstream temperatures, it can act as a barrier against direct solar radiation at the stream surface (Larson \& Larson, 1996). Further work directly exploring the impact of stream shading as a temperature mitigation tool would be useful in developing tools to protect cold-water streams (Broadmeadow, Jones, Langford, Shaw, \& Nisbet, 2011; Gaffield, Potter, \& Wang, 2005; Rutherford, Marsh, Davies, \& Bunn, 2004).

Although air temperature is often used as a strong correlate to stream temperature, we found that this variable alone (Model 1) provided a poor prediction of stream temperature flux at the hourly time scale. However, models that included measures of stream discharge and solar radiation (Models 5 and 6 ) provided relatively good fits to the data, indicating that for many streams, these relatively simple models may be sufficient and provide a cost-effective means of assessing stream temperature dynamics.

\subsection{Model fit and selection}

Adopting a multi-model approach to build models allowed us to use a reproducible statistical methodology and model selection criterion that formalizes the tradeoffs between candidate input variables and the gains in model fit that accrue. Akaike's Information Criteria (AIC) was useful for distinguishing the best model within the hierarchy where models became increasingly complex and contained many of the same or similar parameters. Providing a set of candidate models allowed for the identification of a best approximating model for statistical inference by simultaneously considering goodness of fit and parsimony (Burnham \& Anderson, 2002). Although other researchers provide comparisons among various models (e.g., Beaupré et 
al., 2020; Bustillo et al., 2014; Marcé \& Armengol, 2008), to our knowledge none have used AIC as a means of assessing the tradeoff between model goodness of fit and parsimony. We suggest that such an approach should be employed to provide a sound statistical basis for choosing among candidate models.

Interestingly, the model identified as providing the best overall fit to the observed data contained the greatest number of parameters; however, the reduction in sums of squared errors outweighed the penalties incurred through the high degree of parameterization. Given that stream temperature is dependent upon heat load and stream discharge, it was important to construct models to represent the physical processes governing heat exchange at the stream surface, as well as the influence of various sources of discharge. Many models that have been previously used for representing stream temperature rely on the equilibrium temperature concept (Beaufort et al., 2016; Edinger et al., 1968). These models have been shown to be inadequate for stream reaches with significant input of groundwater, however (e.g., Webb, Hannah, Moore, Brown, \& Nobilis, 2008). In particular, it was important to separate gains in stream discharge into components of baseflow and overland flow as these sources of input have different thermal signatures. Models that lumped the effects of separate components of discharge into a single parameter were not able to represent the dynamics as well as more highly parameterized models which considered the influence of baseflow and overland flow on flux rates.

Separating flow into components representing baseflow and "quickflow" (Koskelo, Fisher, Utz, \& Jordan, 2012) is a complex task. As Koskelo et al. (2012) discuss, the dominant source of baseflow is typically groundwater, but quickflow includes sources such as direct precipitation input, overland flow and shallow subsurface flow (interflow). Each of these components likely has a different thermal signature. We attempted to account for the seasonality of surface runoff temperatures by incorporating a moving average to relate air temperatures to the thermal signature of overland flow, however it would be useful to explore other methods for representing the thermal dynamics of overland or shallow groundwater flow. Additionally, a simple mass balance method was used to predict the baseflow contributions to each stream. Given the complexities described above, we felt that this simplification was adequate, however, a complicating factor was evident in situations where upstream discharge was greater than downstream discharge. These observations indicate the possibility of stream water loss due to infiltration into groundwater or through human diversion of surface water and/or groundwater withdrawal. Stream loss due to surface water diversion would likely have a different impact on flux rates compared to groundwater withdrawal (i.e., reduced baseflow) due to the different thermal signatures. Although we were unable to attribute these stream losses directly to any of the aforementioned sources, these observations highlight an opportunity to evaluate the effects of different types of stream loss on thermal flux rates.

In this research, we chose to model the longitudinal change in stream temperature as a function of potential driving factors rather than model stream temperature directly. Our choice to approach the problem in this way was driven by our desire to embed a systems modeling approach (e.g., Haefner, 2005) that emphasizes system processes and dynamical rates within a statistical framework. In an ecological framework, this approach has been termed an integrated modeling approach where multiple sources of data are combined and analyzed in a unified framework (e.g., Zipkin \& Saunders, 2018). We propose that this approach is useful as it allows data from different sources, and potentially collected at different time intervals, to be included in a statistically rigorous fashion. Further, the coefficients derived from our analyses have direct interpretation for the physical processes that are represented.

\subsection{Future direction}

As the effects of longitudinal flux rates of stream temperature vary on a seasonal and yearly basis, sufficient data must be collected on a range of hydrological and meteorological variables to account for within-year and between-year variation in order to properly calibrate models. Further analysis is needed to examine effects of model components on longitudinal flux rates within seasons. For example, models focused on summer would be particularly useful to water resources management since water withdrawal activities are highest during this time and water temperatures often approach levels stressful to stream biota. While the model selection process showed that it was important to include separate parameters representing the influence of 
each component of discharge on stream temperature, model fit statistics showed the discrepancies between observed and predicted flux rates were generally greatest in late spring/early summer and fall (Figure 5). As evidenced by the seasonal discrepancy, this implies a possible problem with predicting temperatures of groundwater and overland flow since their thermal patterns vary differently with the seasonal weather. Another possible cause is that the amount of riparian shading may vary seasonally, or even spatially due to differences among tree species.

While a general goal of scientific modeling is to provide the most accurate representation of a system possible, the cost of acquiring the data needed to support such models is an important consideration in a resource management context. The comparison among models in a multi-model framework facilitates the systematic evaluation of the tradeoffs between predictive capacity and the cost of supporting model building (e.g., Hansen \& Jones, 2008). Although other statistical analysis tools can be brought to bear on the questions posed in this work, and would potentially provide greater precision, our approach using multiple linear regression within an AIC model selection framework is intended to be accessible to natural resource scientists in an applied management setting. Our hope is that the modeling approach presented in this paper provides practitioners with a practical and useful set of tools for protecting stream habitats.

\section{Acknowledgements}

The authors would like to thank the technicians, Phillip Ankley, Andrew Pawloski, and Katie Kierczynski, for their assistance with field data collection.

Funding: This work was supported by the Michigan Department of Natural Resources. Troy Zorn is employed by the Michigan Department of Natural Resources, and as an author on this manuscript he provided input on the study design, data collection, data analysis, interpretation of results, and editing the manuscript. The decision to submit the article, however, rested solely with Ryan Andrews and Daniel Hayes.

\section{References}

Akaike, H. (1998). Information theory and an extension of the maximum likelihood principle. In Selected papers of Hirotugu Akaike, (pp. 199-213). Springer, New York, NY. https://doi.org/10.1007/978-1-46121694-0_15

Beaufort, A., Curie, F., Moatar, F., Ducharne, A., Melin, E., \& Thiery, D. (2016). T-NET, a dynamic model for simulating daily stream temperature at the regional scale based on a network topology.Hydrological Processes , 30 (13), 2196-2210.

Beaupré, L., St.-Hilaire, A., Daigle, A., \& Bergeron, N. (2020). Comparison of a deterministic and statistical approach for the prediction of thermal indices in regulated and unregulated river reaches: case study of the Fourchue River (Quebec, Canada). Water Quality Research Journal , 55 (4), 394-408. doi: 10.2166/wqrj.2020.001

Broadmeadow, S.B., Jones, J.G., Langford, T.E.L., Shaw, P.J., \& Nisbet, T.R. (2011). The influence of riparian shade on lowland stream water temperatures in southern England and their viability for brown trout. River Research and Applications, 27 (2), 226-237. https://doi.org/10.1002/rra.1354

Burnham, K.P., Anderson, D.R., 2002. A Practical Information-Theoretic Approach. Model Selection and Inference, (2nd ed.). Springer, New York. ISBN: 0-387-95364-7.

Bustillo, V., Moatar, F., Ducharne, A., Thiéry, D., \& Poirel, A. (2014). A multimodel comparison for assessing water temperatures under changing climate conditions via the equilibrium temperature concept: a case study of the Middle Loire River, France. Hydrological Processes , 28 (3), 1507-1524.

Caissie, D. (2006). The thermal regime of rivers: A review.Freshwater Biology , 51 (8), 1389-1406. https://doi.org/10.1111/j.1365-2427.2006.01597.x

Collins, W.D., 1925. Temperature of water available for industrial use in the United States, in: Grover, N.C., Contributions to the Hydrology of the United States 1923-1924. US Government Printing Office, (pp. 
97-105).

Edinger, J.E., Duttweiler, D.W., \& Geyer, J.C. (1968). The response of water temperature to meteorological conditions. Water Resources Research , 4 (5), 1137-1143.

Fletcher, T.D., 2012. QuantPsyc: quantitative psychology tools. R Package. Version 1.5.

Gaffield, S.J., Potter, K.W., \& Wang, L. (2005). Predicting the summer temperature of small streams in southwestern Wisconsin. Journal of the American Water Resources Association, 41 (1), 25-36. https://doi.org/10.1111/j.1752-1688.2005.tb03714.x

Haefner, J.W. (2005). Modeling biological systems: Principles and applications, Springer Science \& Business Media, New York. https://doi.org/10.1007/0-387-25012-3_1

Hansen, G.J.A., \& Jones, M.L. (2008). The value of information in fishery management. Fisheries , 33 (7), 340-348. https://doi.org/10.1577/1548-8446-33.7.340

Herb, W.R., \& Stefan, H.G. (2011). Modified equilibrium temperature models for cold-water streams. Water Resources Research, 47 (6). https://doi.org/10.1029/2010WR009586

Johnson, S.L. (2004). Factors influencing stream temperatures in small streams: Substrate effects and a shading experiment. Canadian Journal of Fisheries and Aquatic Sciences , 61 (6), 913-923. https://doi.org/10.1139/F04-040

Koskelo, A.I., Fisher, T.R., Utz, R.M., \& Jordan, T.E. (2012). A new precipitation-based method of baseflow separation and event identification for small watersheds $\left(<50 \mathrm{~km}^{2}\right)$. Journal of Hydrology , 450 , 267-278.

Larson, L.L., \& Larson, S.L. (1997). Riparian shade and stream temperature: An alternative perspective. Rangelands ,19 (2), 25-28.

Magnusson, J., Jonas, T., \& Kirchner, J.W. (2012). Temperature dynamics of a proglacial stream: Identifying dominant energy balance components and inferring spatially integrated hydraulic geometry. Water Resources Research , 48 (6), 1-16. https://doi.org/10.1029/2011WR011378

Marcé, R., \& Armengol. J. (2008). Modelling river water temperature using a deterministic, empirical, and hybrid formulations in a Mediterranean stream. Hydrological Processes , 22 (17), 3418-3430.

Meeus, J.H. (1999). Astronomical algorithms, (2nd ed.). Willmann-Bell, Incorporated, Richmond.

Michigan Department of Environmental Quality, (2005). Groundwater Inventory and Map Project. Public Act 148, Lansing.

Naiman, R.J., Magnuson, J.J., McKnight, D.M., \& Stanford, J.A. (1995). The freshwater imperative: A research agenda. Island Press, Washington, DC. https://doi.org/10.5860/choice.34-0906

Poole, G.C., \& Berman, C.H. (2001). An ecological perspective on in-stream temperature: Natural heat dynamics and mechanisms of human-caused thermal degradation. Environmental Management ,27 (6), 787802. https://doi.org/10.1007/s002670010188

Rantz, S.E. (1982). Measurement and computation of streamflow: volume 1. Measurement of stage and discharge. US Geological Survey Water-Supply Paper 2175. https://doi.org/10.3133\%2Fwsp2175_vol1

Risley, J.C., Constantz, J., Essaid, H., \& Rounds, S. (2010). Effects of upstream dams versus groundwater pumping on stream temperature under varying climate conditions. Water Resources Research ,46 (6). https://doi.org/10.1029/2009WR008587

Rutherford, J.C., Marsh, N.A., Davies, P.M., \& Bunn, S.E. (2004). Effects of patchy shade on stream water temperature: How quickly do small streams heat and cool? Marine and Freshwater Research ,55 (8), 737-748. https://doi.org/10.1071/MF04120 
Seelbach, P.W., Wiley, M.J., Kotanchik, J.C., \& Baker, M.E. (1997). A landscape-based ecological classification system for river valley segments in lower Michigan (MI-VSEC version 1.0). Fisheries Research

Stanford, J.A., \& Ward, J. V. (1993). An ecosystem perspective of alluvial rivers: Connectivity and the hyporheic corridor. Journal of the North American Benthological Society , 12 (1), 48-60. https://doi.org/10.2307/1467685

Stefan, H.G., \& Preud'homme, E.B. (1993). Stream temperature estimation from air temperature. Journal of the American Water Resources Association , 29 (1), 27-45. https://doi.org/10.1111/j.17521688.1993.tb01502.x

Team, R. C. (2013). R: A language and environment for statistical computing.

Thayer, S.A., Taylor, W.W., Hayes, D.B., \& Haas, R.C. (2007). Weight of evidence for underlying dynamics of yellow perch in Saginaw Bay, Lake Huron. Ecological Modelling , 206 (1-2), 31-40. https://doi.org/10.1016/j.ecolmodel.2007.03.012

Theurer, F., Voos, D., Kenneth, A., \& Miller, W.J. (1984). Instream water temperature model. Instream Flow Information Paper16 (No. 84/15). U.S. Fish and Wildlife Service, Fort Collins, CO.

Webb, B.W., Hannah, D.M., Moore, R.D., Brown, L.E., \& Nobilis. F. (2008). Recent advances in stream and river temperature research.Hydrological Processes, 22 (7), 902-918.

Wondzell, S.M., Diabat, M., \& Haggerty, R. (2019). What matters most: Are future stream temperatures more sensitive to changing air temperatures, discharge, or riparian vegetation? Journal of the American Water Resources Association , 55 (1), 116-132. https://doi.org/10.1111/1752-1688.12707

Zipkin, E.F., \& Saunders, S.P. (2018). Synthesizing multiple data types for biological conservation using integrated population models.Biological Conservation , 217 , 240-250. https://doi.org/10.1016/j.biocon.2017.10.017

Table 1: Site information specific to each stream segment. Streams marked with ${ }^{+}$are those for which data were collected for both the 2015 and 2016 field seasons. Up and down refer to upstream and downstream locations. Streams are arranged by ascending groundwater temperature, based on Collins (1925).

\begin{tabular}{|c|c|c|c|c|c|c|c|}
\hline Stream & Site Code & $\begin{array}{l}\text { Up Latitude } \\
\text { (DD) }\end{array}$ & $\begin{array}{l}\text { Up } \\
\text { Longitude } \\
\text { (DD) }\end{array}$ & $\begin{array}{l}\text { Down } \\
\text { Latitude } \\
\text { (DD) }\end{array}$ & $\begin{array}{l}\text { Down } \\
\text { Longitude } \\
\text { (DD) }\end{array}$ & $\begin{array}{l}\text { Reach } \\
\text { Length (m) }\end{array}$ & $\begin{array}{l}\text { Groundwater } \\
\text { Temperature } \\
\left({ }^{\circ} \mathrm{C}\right)\end{array}$ \\
\hline $\begin{array}{l}\text { Morgan } \\
\text { Creek }^{+}\end{array}$ & $\mathrm{MC}$ & 46.519698 & -87.504502 & 46.521351 & -87.494782 & 1,106 & 5.6 \\
\hline $\begin{array}{l}\text { Carp } \\
\text { River }\end{array}$ & $\mathrm{CA}$ & 46.509131 & -87.418924 & 46.510534 & -87.388497 & 2,614 & 5.6 \\
\hline $\begin{array}{l}\text { Slapneck } \\
\text { Creek }\end{array}$ & SL & 46.354843 & -86.946771 & 46.350637 & -86.928918 & 1,564 & 5.6 \\
\hline $\begin{array}{l}\text { Spring } \\
\text { Creek }^{+}\end{array}$ & SP & 46.512909 & -90.156133 & 46.513418 & -90.177011 & 1,681 & 5.6 \\
\hline $\begin{array}{l}\text { Middle } \\
\text { Branch } \\
\text { Escanaba } \\
\text { River }\end{array}$ & $\mathrm{ER}$ & 46.420206 & -87.797962 & 46.398398 & -87.770883 & 6,131 & 5.6 \\
\hline $\begin{array}{l}\text { Squaw } \\
\text { Creek }\end{array}$ & SQ & 46.057035 & -87.18974 & 45.985396 & -87.140559 & 1,676 & 5.6 \\
\hline $\begin{array}{l}\text { Cedar } \\
\text { Creek }\end{array}$ & $\mathrm{CC}$ & 44.375846 & -85.972647 & 44.369588 & -85.999598 & 2,551 & 8.3 \\
\hline
\end{tabular}




\begin{tabular}{|c|c|c|c|c|c|c|c|}
\hline Stream & Site Code & $\begin{array}{l}\text { Up Latitude } \\
\text { (DD) }\end{array}$ & $\begin{array}{l}\text { Up } \\
\text { Longitude } \\
\text { (DD) }\end{array}$ & $\begin{array}{l}\text { Down } \\
\text { Latitude } \\
\text { (DD) }\end{array}$ & $\begin{array}{l}\text { Down } \\
\text { Longitude } \\
\text { (DD) }\end{array}$ & $\begin{array}{l}\text { Reach } \\
\text { Length (m) }\end{array}$ & $\begin{array}{l}\text { Groundwater } \\
\text { Temperature } \\
\left({ }^{\circ} \mathrm{C}\right)\end{array}$ \\
\hline $\begin{array}{l}\text { Cedar } \\
\text { River }^{+}\end{array}$ & $\mathrm{CR}$ & 44.956875 & -85.132748 & 44.968664 & -85.138993 & 1,454 & 8.3 \\
\hline $\begin{array}{l}\text { East } \\
\text { Branch } \\
\text { Black } \\
\text { River }\end{array}$ & EB & 45.070651 & -84.283728 & 45.089439 & -84.284929 & 2,879 & 8.3 \\
\hline $\begin{array}{l}\text { Butterfield } \\
\text { Creek }^{+}\end{array}$ & $\mathrm{BC}$ & 44.273249 & -85.094087 & 44.256377 & -85.03362 & 5,978 & 8.3 \\
\hline $\begin{array}{l}\text { King } \\
\text { Creek }\end{array}$ & $\mathrm{KC}$ & 45.018848 & -83.650705 & 45.047993 & -83.634655 & 5,822 & 8.3 \\
\hline $\begin{array}{l}\text { North } \\
\text { Branch } \\
\text { Thunder } \\
\text { Bay River }\end{array}$ & NB & 45.179007 & -83.923148 & 45.191635 & -83.891476 & 4,630 & 8.3 \\
\hline $\begin{array}{l}\text { Fish } \\
\text { Creek }^{+}\end{array}$ & $\mathrm{FC}$ & 43.245992 & -84.964747 & 43.242022 & -84.915223 & 5,186 & 11.1 \\
\hline $\begin{array}{l}\text { Pokagon } \\
\text { Creek }^{+}\end{array}$ & $\mathrm{PC}$ & 41.89517 & -86.162632 & 41.915803 & -86.175679 & 4,050 & 11.1 \\
\hline $\begin{array}{l}\text { Pigeon } \\
\text { River }^{+}\end{array}$ & PI & 42.932887 & -86.081828 & 42.91636 & -86.146075 & 6,550 & 11.1 \\
\hline $\begin{array}{l}\text { Honeyoey } \\
\text { Creek }\end{array}$ & $\mathrm{HC}$ & 43.433623 & -84.701648 & 43.379136 & -84.705982 & 6,638 & 11.1 \\
\hline $\begin{array}{l}\text { Middle } \\
\text { Branch } \\
\text { Tobacco } \\
\text { River }\end{array}$ & MB & 43.909194 & -84.697312 & 43.929905 & -84.666327 & 4,091 & 11.1 \\
\hline $\begin{array}{l}\text { Nottawa } \\
\text { Creek }^{+}\end{array}$ & $\mathrm{NC}$ & 42.192564 & -85.060415 & 42.195998 & -85.104618 & 3,758 & 11.1 \\
\hline $\begin{array}{l}\text { Hasler } \\
\text { Creek }\end{array}$ & HA & 43.042332 & -83.423206 & 43.083594 & -83.442947 & 7,586 & 11.1 \\
\hline $\begin{array}{l}\text { Prairie } \\
\text { River }^{+}\end{array}$ & PR & 41.801832 & -85.116614 & 41.832568 & -85.165065 & 5,863 & 11.1 \\
\hline $\begin{array}{l}\text { Swan } \\
\text { Creek }\end{array}$ & $\mathrm{SC}$ & 41.90477 & -85.297885 & 41.921249 & -85.312047 & 2,539 & 11.1 \\
\hline
\end{tabular}

Table 2: Model numbers and the parameters included within each model denoted with an $\mathrm{X} . T_{a}=$ air temperature $\left({ }^{\circ} \mathrm{C}\right) ; T_{w}=$ water temperature $\left({ }^{\circ} \mathrm{C}\right) ; Q_{u p}=$ upstream discharge $\left(\mathrm{m}^{3} / \mathrm{s}\right) ; Q_{\text {down }}=$ downstream discharge $\left(\mathrm{m}^{3} / \mathrm{s}\right) ; S=$ day length $(\mathrm{hr}) ; \Delta_{\varphi \lambda o \omega}=$ cumulative heat energy $\left({ }^{\circ} \mathrm{C}\right) ; \Delta_{v \pi}=$ upstream heat energy $\left({ }^{\circ} \mathrm{C}\right) ; \Delta_{\beta a \sigma \epsilon}=$ baseflow heat energy $\left({ }^{\circ} \mathrm{C}\right) ; \Delta_{o \epsilon \rho}=$ overland flow heat energy $\left({ }^{\circ} \mathrm{C}\right) ; a=$ sun altitude angle $\left({ }^{\circ}\right)$.

\begin{tabular}{ll}
\hline Model Number & Equation \\
\hline 1 & $\Delta T=\beta_{0}+\beta_{1}\left(T_{a}-T_{w}\right)$ \\
2 & $\Delta T=\beta_{0}+\beta_{1}\left(T_{a}-T_{w}\right)+\beta_{2}\left(Q_{d} / Q_{u}\right)$ \\
3 & $\Delta T=\beta_{0}+\beta_{1}\left(T_{a}-T_{w}\right)+\beta_{3}\left(Q_{u}\right)+\beta_{4}\left(\Delta_{\varphi \lambda o \omega}\right)$ \\
4 & $\Delta T=\beta_{0}+\beta_{1}\left(T_{a}-T_{w}\right)+\beta_{3}\left(Q_{u}\right)+\beta_{4}\left(\Delta_{\varphi \lambda o \omega}\right)+\beta_{5}\left(Q_{d}-Q_{u}\right)$ \\
5 & $\Delta T=\beta_{0}+\beta_{1}\left(T_{a}-T_{w}\right)+\beta_{3}\left(Q_{u}\right)+\beta_{4}\left(\Delta_{\varphi \lambda o \omega}\right)+\beta_{5}\left(Q_{d}-Q_{u}\right)+\beta_{6}(S)$ \\
6 & $\Delta T=\beta_{0}+\beta_{1}\left(T_{a}-T_{w}\right)+\beta_{3}\left(Q_{u}\right)+\beta_{4}\left(\Delta_{\varphi \lambda o \omega}\right)+\beta_{5}\left(Q_{d}-Q_{u}\right)+\beta_{7}(a)$
\end{tabular}




\begin{tabular}{|c|c|}
\hline Model Number & Equation \\
\hline 7 & $\Delta T=\beta_{0}+\beta_{1}\left(T_{a}-T_{w}\right)+\beta_{3}\left(Q_{u}\right)+\beta_{4}\left(\Delta_{\varphi \lambda o \omega}\right)+\beta_{5}\left(Q_{d}-Q_{u}\right)+\beta_{6}(S)+\beta_{7}(a)$ \\
\hline 8 & $\Delta T=\beta_{0}+\beta_{1}\left(T_{a}-T_{w}\right)+\beta_{3}\left(Q_{u}\right)+\beta_{4}\left(\Delta_{\varphi \lambda o \omega}\right)+\beta_{5}\left(Q_{d}-Q_{u}\right)+\beta_{6}(S)+\beta_{7}(a)+\beta_{8}\left(\Delta_{v \pi}\right)+\beta_{9}\left(\Delta_{\beta}\right.$ \\
\hline 9 & $\Delta T=\beta_{0}+\beta_{1}\left(T_{a}-T_{w}\right)+\beta_{3}\left(Q_{u}\right)+\beta_{4}\left(\Delta_{\varphi \lambda o \omega}\right)+\beta_{5}\left(Q_{d}-Q_{u}\right)+\beta_{7}(a)+\beta_{8}\left(\Delta_{v \pi}\right)+\beta_{9}\left(\Delta_{\beta a \sigma \epsilon}\right)+\beta_{10}$ \\
\hline 10 & $\Delta T=\beta_{0}+\beta_{1}\left(T_{a}-T_{w}\right)+\beta_{3}\left(Q_{u}\right)+\beta_{4}\left(\Delta_{\varphi \lambda o \omega}\right)+\beta_{5}\left(Q_{d}-Q_{u}\right)+\beta_{6}(S)+\beta_{8}\left(\Delta_{v \pi}\right)+\beta_{9}\left(\Delta_{\beta a \sigma \epsilon}\right)+\beta_{10}$ \\
\hline 11 & $\Delta T=\beta_{0}+\beta_{1}\left(T_{a}-T_{w}\right)+\beta_{9}\left(\Delta_{\beta a \sigma \epsilon}\right)+\beta_{10}\left(\Delta_{o \epsilon \rho}\right)+\beta_{12}\left(\left[\left(T_{w}+273.16\right)^{4} / Q\right]\right)+\beta_{13}\left(\left[\left(\exp \left(T_{w}\right)-\exp (\right.\right.\right.$ \\
\hline
\end{tabular}

Table 3: Summary of hydrological and thermal characteristics of study reaches. Values are averaged over the entire study period for each study stream. Change in discharge was calculated such that positive values indicate longitudinal gains in discharge. Streams are sorted in order of flux rate from warming to cooling.

\begin{tabular}{lllll}
\hline Stream & Air Temperature $\left({ }^{\circ} \mathrm{C}\right)$ & Up Discharge $\left(\mathrm{m}^{3} / \mathrm{s}\right)$ & Down Discharge $\left(\mathrm{m}^{3} / \mathrm{s}\right)$ & Width/Dept \\
\hline Squaw Creek & 17.47 & 0.04 & 0.12 & 14.21 \\
Cedar River & 16.89 & 1.34 & 1.78 & 19.89 \\
Honeyoey Creek & 19.90 & 0.06 & 0.08 & 10.16 \\
Slapneck Creek & 17.01 & 0.33 & 1.04 & 10.55 \\
Middle Branch Tobacco River & 20.01 & 0.52 & 0.53 & 18.27 \\
Swan Creek & 20.20 & 0.38 & 0.48 & 27.39 \\
North Branch Thunder Bay River & 16.64 & 0.43 & 0.40 & 16.84 \\
East Branch Black River & 19.09 & 0.83 & 0.73 & 12.73 \\
Pokagon Creek & 18.49 & 0.42 & 0.41 & 13.62 \\
King Creek & 16.64 & 0.01 & 0.01 & 26.67 \\
Fish Creek & 18.49 & 0.86 & 1.08 & 21.24 \\
Prairie River & 19.24 & 0.21 & 0.28 & 16.33 \\
Cedar Creek & 17.68 & 0.12 & 0.56 & 25.84 \\
Carp River & 15.67 & 1.79 & 1.34 & 25.41 \\
Middle Branch Escanaba River & 15.72 & 0.99 & 1.27 & 18.57 \\
Spring Creek & 15.62 & 0.12 & 0.20 & 18.08 \\
Pigeon River & 18.21 & 0.48 & 0.60 & 17.96 \\
Butterfield Creek & 16.90 & 0.09 & 0.19 & 18.16 \\
Morgan Creek & 15.69 & 0.11 & 0.14 & 31.60 \\
Nottawa Creek & 19.18 & 0.55 & 0.62 & 19.00 \\
Hasler Creek & 17.14 & 0.04 & 0.09 & \\
\hline
\end{tabular}

Table 4: Average monthly downstream thermal flux rates $\left({ }^{\circ} \mathrm{C} / \mathrm{km}\right)$ of each study stream. Streams are arranged from highest to lowest flux rates during mid-summer months (July-August)

\begin{tabular}{lcccllll}
\hline Stream & May & June & July & August & September & October & November \\
\hline Squaw Creek & & 0.37 & 0.85 & 0.66 & 0.49 & 0.44 & \\
Cedar River & 0.27 & 0.26 & 0.31 & 0.32 & 0.25 & 0.07 & -0.02 \\
Honeyoey Creek & 0.06 & 0.16 & 0.28 & 0.24 & 0.15 & 0.01 & \\
Swan Creek & 0.04 & 0.03 & 0.24 & 0.21 & 0.03 & 0.05 & \\
Slapneck Creek & & 0.12 & 0.30 & 0.16 & 0.04 & 0.01 & \\
Middle Branch Tobacco River & 0.12 & 0.13 & 0.17 & 0.16 & 0.12 & 0.07 & \\
North Branch Thunder Bay River & & & 0.12 & 0.16 & 0.05 & 0.03 & 0.01 \\
King Creek & & & 0.13 & 0.12 & 0.06 & 0.03 & -0.04 \\
Pokagon Creek & 0.07 & 0.11 & 0.12 & 0.11 & 0.10 & -0.01 & -0.03 \\
East Branch Black River & & 0.09 & 0.08 & 0.08 & 0.05 & 0.04 &
\end{tabular}




\begin{tabular}{llllllll}
\hline Stream & May & June & July & August & September & October & November \\
\hline Cedar Creek & 0.04 & 0.05 & 0.07 & 0.07 & -0.04 & -0.09 & \\
Fish Creek & 0.01 & 0.04 & 0.08 & 0.06 & 0.01 & 0.01 & 0.01 \\
Prairie River & 0.03 & 0.05 & 0.08 & 0.06 & 0.03 & -0.01 & -0.01 \\
Carp River & & -0.03 & 0.01 & 0.03 & 0.03 & 0.04 & 0.08 \\
Middle Branch Escanaba River & & 0.07 & 0.10 & -0.01 & -0.13 & -0.17 & \\
Pigeon River & -0.06 & -0.06 & -0.02 & -0.04 & -0.10 & -0.06 & -0.02 \\
Spring Creek & & -0.13 & -0.16 & -0.06 & 0.04 & -0.01 & 0.05 \\
Butterfield Creek & -0.13 & -0.18 & -0.18 & -0.15 & -0.09 & -0.02 & 0.03 \\
Morgan Creek & & -0.38 & -0.24 & -0.16 & -0.12 & -0.08 & -0.09 \\
Nottawa Creek & -0.12 & -0.19 & -0.21 & -0.22 & -0.22 & -0.12 & -0.02 \\
Hasler Creek & & -0.39 & -0.41 & -0.42 & -0.30 & -0.14 & -0.02 \\
Overall Mean & 0.03 & 0.01 & 0.08 & 0.07 & 0.02 & 0.00 & -0.01 \\
\hline
\end{tabular}

Table 5: Measures of goodness of fit for each model, averaged across all study streams. Models are ranked based upon mean weight of evidence in descending order. Results represent averages over each study stream for the entire study period. $\mathrm{K}=$ number of model parameters; AIC = Akaike Information Criterion; $\omega=$ Akaike weight; Count $=$ total number of streams for which each model was identified as providing the best fit.

\begin{tabular}{llllll}
\hline Model & $\mathrm{K}$ & $\mathrm{R}^{2}$ & $\mathrm{AIC}$ & $\omega$ & Count \\
\hline 10 & 9 & 0.41 & -6826 & 0.695 & 15 \\
11 & 7 & 0.29 & -6072 & 0.238 & 5 \\
9 & 8 & 0.34 & -6344 & 0.065 & 1 \\
8 & 8 & 0.37 & -6503 & 0.001 & 0 \\
7 & 7 & 0.36 & -6390 & 0.000 & 0 \\
5 & 6 & 0.32 & -6086 & 0.000 & 0 \\
6 & 6 & 0.28 & -5893 & 0.000 & 0 \\
4 & 5 & 0.24 & -5613 & 0.000 & 0 \\
3 & 4 & 0.20 & -5360 & 0.000 & 0 \\
2 & 3 & 0.15 & -5044 & 0.000 & 0 \\
1 & 2 & 0.07 & -4625 & 0.000 & 0 \\
\hline
\end{tabular}

Table 6: Partial $\mathrm{R}^{2}$ values for each stream for Model 10. Streams are ordered based upon $\mathrm{R}^{2}$ of Model 10. Values represent the proportion of variation which cannot be explained by the predictors in the reduced model when compared to the full model. $\omega$ represents the model weight of Model 10 . Overall $\mathrm{R}^{2}$ values represent fit between observed and predicted values using Model 10.

\begin{tabular}{lllllllllll}
\hline Stream & $\mathrm{T}_{\mathrm{a}}-\mathrm{T}_{\text {up }}$ & $\mathrm{Q}_{\mathrm{up}}$ & $\mathrm{Q}_{\text {down }}-\mathrm{Q}_{\mathrm{up}}$ & $\mathrm{S}$ & $\Delta_{\text {up }}$ & $\Delta_{\text {base }}$ & $\Delta_{\text {over }}$ & $\alpha$ & $\omega$ & Overall R $^{2}$ \\
\hline Middle Branch Tobacco River & 0.03 & 0.10 & 0.02 & 0.60 & 0.01 & 0.00 & 0.00 & 0.19 & 0 & 0.77 \\
Hasler Creek & 0.04 & 0.05 & 0.00 & 0.07 & 0.00 & 0.02 & 0.02 & 0.03 & 1 & 0.71 \\
Middle Branch Escanaba River & 0.00 & 0.00 & 0.03 & 0.05 & 0.00 & 0.03 & 0.03 & 0.07 & 0.974 & 0.71 \\
Cedar Creek & 0.02 & 0.01 & 0.00 & 0.23 & 0.02 & 0.03 & 0.05 & 0.01 & 1 & 0.62 \\
Butterfield Creek & 0.04 & 0.03 & 0.00 & 0.10 & 0.08 & 0.00 & 0.12 & 0.01 & 1 & 0.59 \\
Fish Creek & 0.02 & 0.01 & 0.00 & 0.00 & 0.06 & 0.07 & 0.16 & 0.10 & 0 & 0.57 \\
Honeyoey Creek & 0.00 & 0.00 & 0.00 & 0.14 & 0.00 & 0.07 & 0.06 & 0.01 & 0.998 & 0.50 \\
North Branch Thunder Bay River & 0.00 & 0.00 & 0.00 & 0.00 & 0.00 & 0.01 & 0.01 & 0.14 & 0 & 0.47 \\
Morgan Creek & 0.00 & 0.00 & 0.01 & 0.24 & 0.00 & 0.00 & 0.00 & 0.05 & 0.998 & 0.42
\end{tabular}




\begin{tabular}{lllllllllll}
\hline Stream & $\mathrm{T}_{\mathrm{a}}-\mathrm{T}_{\mathrm{up}}$ & $\mathrm{Q}_{\mathrm{up}}$ & $\mathrm{Q}_{\text {down }}-\mathrm{Q}_{\mathrm{up}}$ & $\mathrm{S}$ & $\Delta_{\text {up }}$ & $\Delta_{\text {base }}$ & $\Delta_{\text {over }}$ & $\alpha$ & $\omega$ & Overall $^{2}$ \\
\hline Slapneck Creek & 0.02 & 0.20 & 0.04 & 0.06 & 0.00 & 0.00 & 0.00 & 0.02 & 1 & 0.35 \\
King Creek & 0.14 & 0.02 & 0.00 & 0.00 & 0.05 & 0.19 & 0.12 & 0.02 & 1 & 0.33 \\
Nottawa Creek & 0.10 & 0.01 & 0.00 & 0.00 & 0.03 & 0.04 & 0.04 & 0.47 & 1 & 0.32 \\
Cedar River & 0.03 & 0.02 & 0.00 & 0.18 & 0.00 & 0.00 & 0.00 & 0.06 & 1 & 0.30 \\
Prairie River & 0.01 & 0.10 & 0.00 & 0.09 & 0.04 & 0.00 & 0.01 & 0.05 & 1 & 0.30 \\
Pigeon River & 0.09 & 0.00 & 0.05 & 0.01 & 0.05 & 0.00 & 0.00 & 0.01 & 1 & 0.30 \\
Pokagon Creek & 0.01 & 0.05 & 0.00 & 0.00 & 0.07 & 0.15 & 0.16 & 0.00 & 1 & 0.30 \\
Squaw Creek & 0.15 & 0.00 & 0.00 & 0.04 & 0.05 & 0.06 & 0.06 & 0.06 & 1 & 0.26 \\
Carp River & 0.07 & 0.00 & 0.01 & 0.05 & 0.03 & 0.11 & 0.05 & 0.04 & 1 & 0.24 \\
Swan Creek & 0.00 & 0.02 & 0.00 & 0.00 & 0.07 & 0.10 & 0.05 & 0.00 & 0.505 & 0.23 \\
East Branch Black River & 0.02 & 0.00 & 0.00 & 0.02 & 0.00 & 0.00 & 0.00 & 0.12 & 0 & 0.19 \\
Spring Creek & 0.05 & 0.00 & 0.01 & 0.00 & 0.00 & 0.00 & 0.00 & 0.01 & 0 & 0.16 \\
Overall Mean & 0.04 & 0.03 & 0.01 & 0.09 & 0.03 & 0.04 & 0.04 & 0.07 & 0.695 & 0.41 \\
\hline
\end{tabular}

\section{Study Stream Locations}

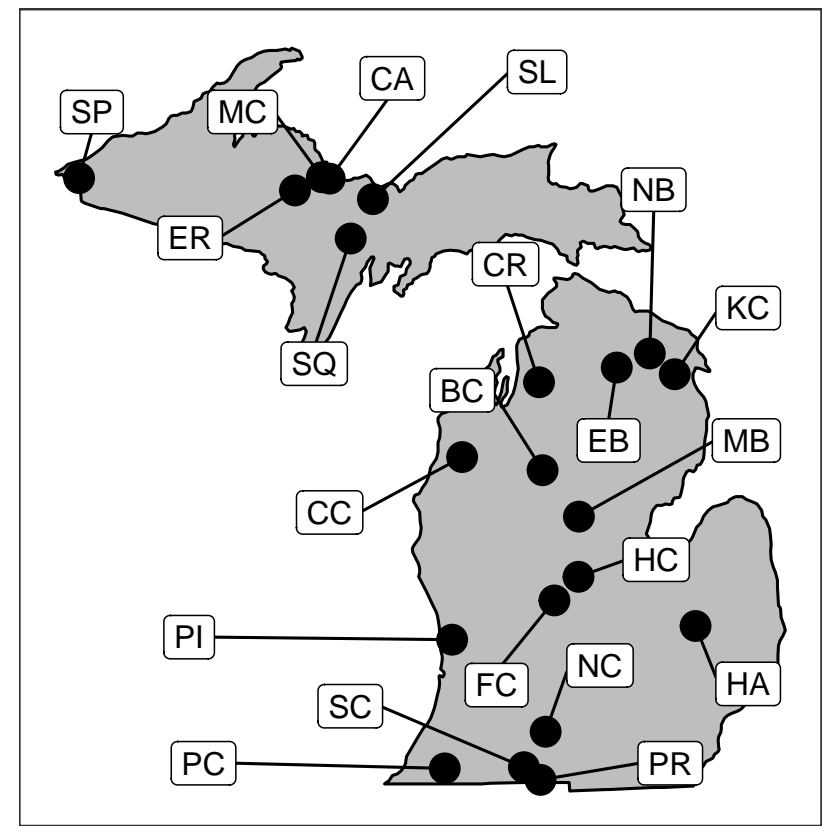


Cedar River

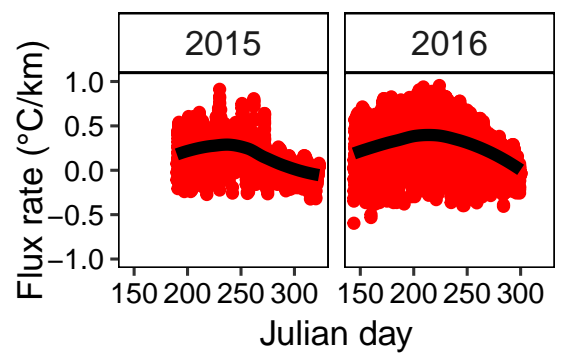

Prairie River

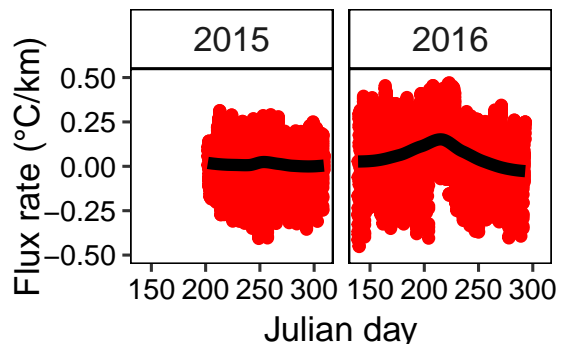
Julian day

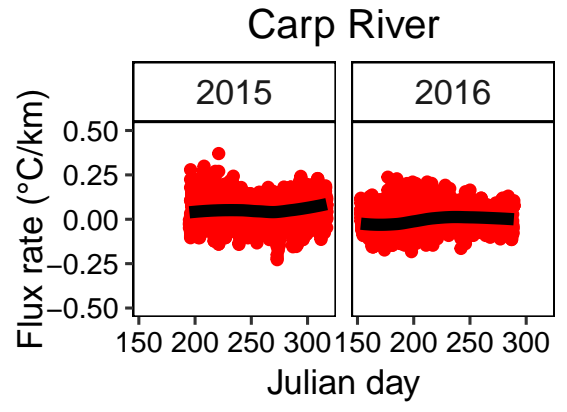

Nottawa Creek

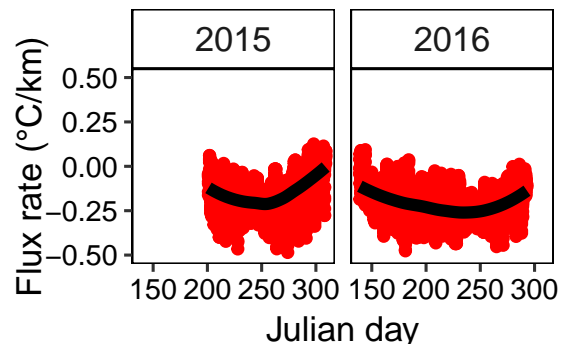

- Observed Loess
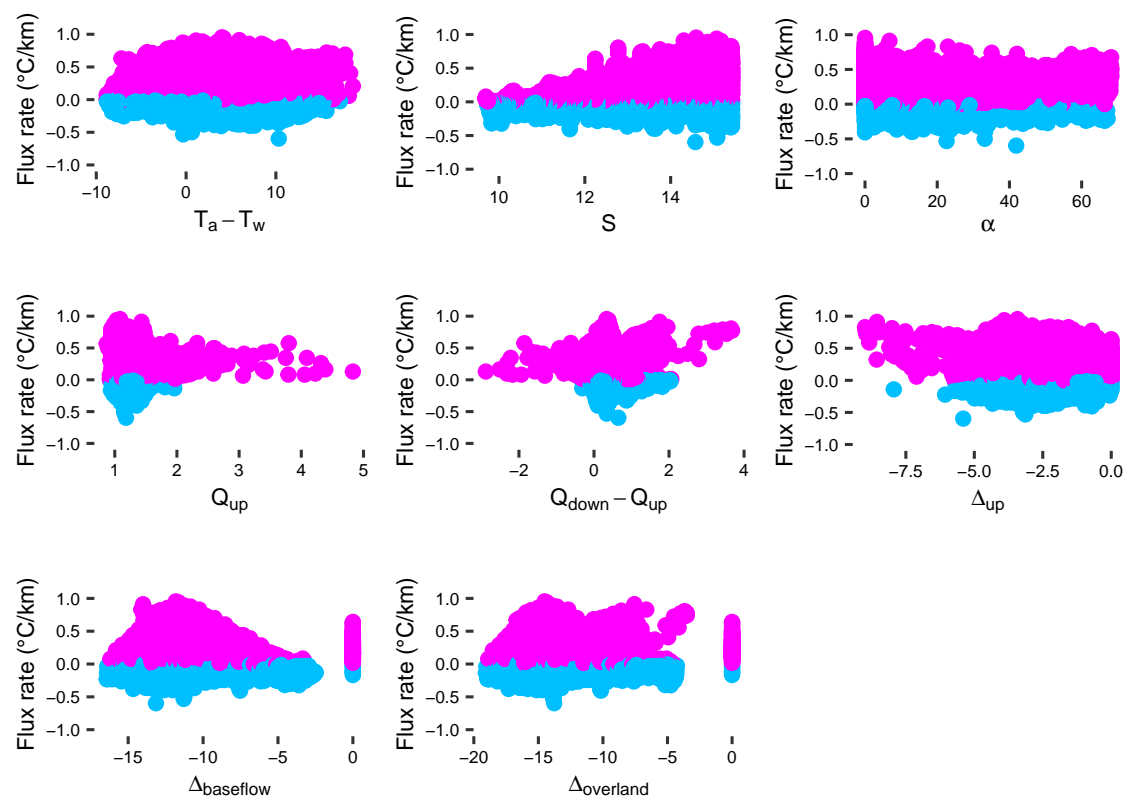

Flux Cooling

Warming 

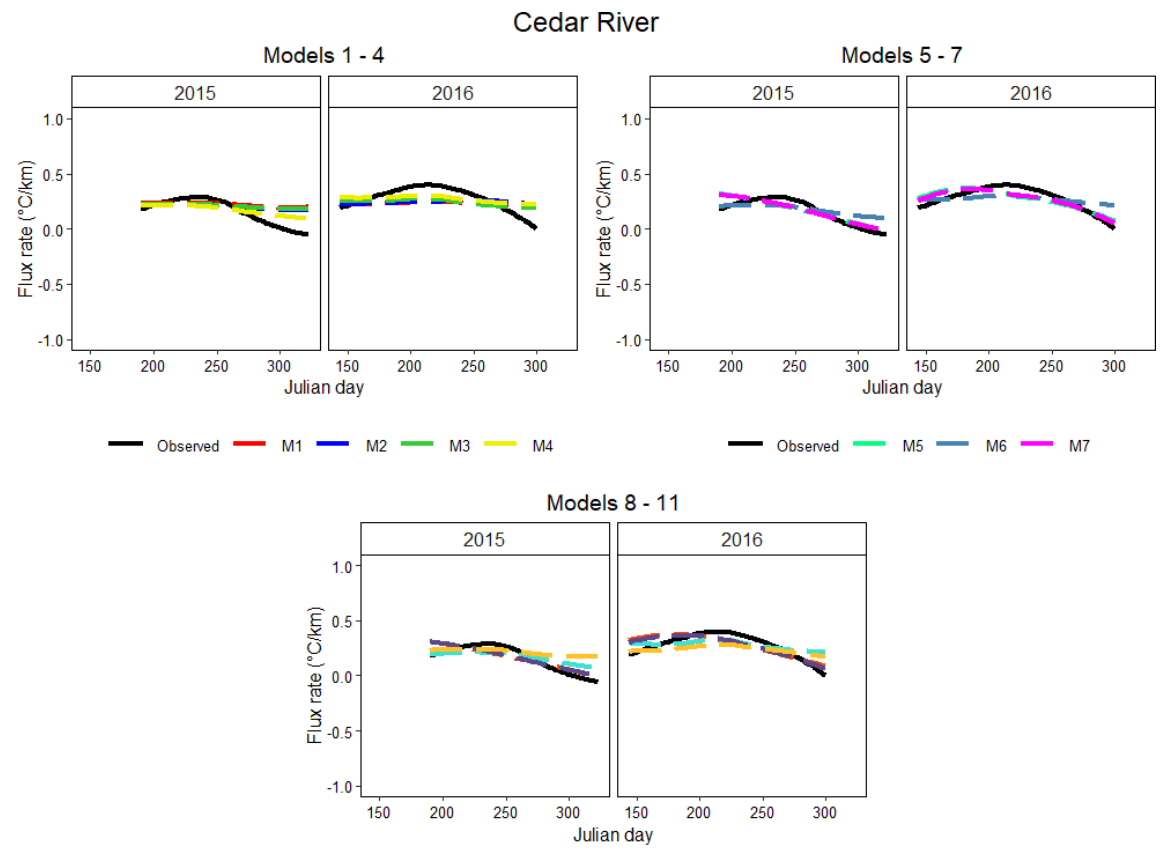

- Observed - $\mathrm{M8}-\mathrm{M} 9-\mathrm{M} 10-\mathrm{M} 11$
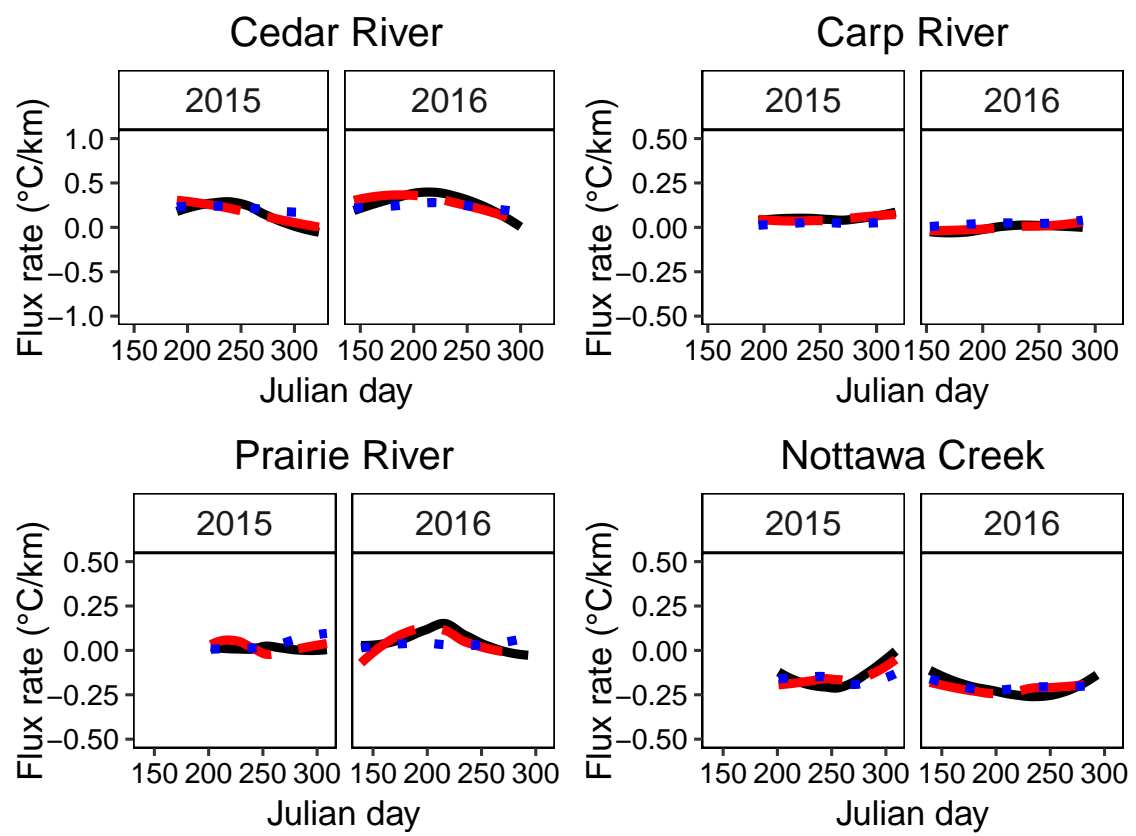

Observed $=$ M10 - M11 